Institute of $\mathbf{F}_{\text {ood and }} \mathbf{A}$ gricultural $\mathbf{S}_{\text {ciences }}$

\title{
Sustainability Aspects of Precision Agriculture for Row Crops in Florida and the Southeast U.S. 1
}

\section{L. Wright, J. J. Marois, and J. R. Rich ${ }^{2}$}

Precision farming or site-specific management has been defined as a knowledge-based technical management system that can optimize farm profits and minimize agriculture's impact on the environment. Information about a field can be obtained and continuously updated to refine management strategies. Precision farming involves using what we know about fields and correlating that to responses from specific management decisions under those conditions. Precision farming uses research data which is translated into a hoped-for economic response. Stated another way, it is the determination of inputs needed for profitable management decisions. Growers who get involved in site-specific farming have more information at their disposal and usually spend more time thinking about crop management and how yields may be influenced.

\section{Where We Came From and Current Status}

Agricultural research has always attempted to determine precise responses under controlled or known conditions. In research plots, scientists control as many factors as possible, then study variables to determine if treatments are practical and under what conditions a response might be expected. Farmers, likewise, want as much information as possible from soil tests, pest maps, and other information sources to make informed management decisions. In many cases, growers have no way to check responses to rates of materials applied but have a good idea of what happens without that input. As soybean for grain was introduced, for example, a knowledge of soil $\mathrm{pH}$ was needed for lime application so that good growth of bacteria would occur and thus enhance crop productivity. However, growers have had little way to confirm whether low, medium, or high liming rates were most economical. Early researchers determined fertility level of the soil or water holding capacity on specific sites or fields and made recommendations for the proper lime application for most economic returns. Variety evaluations, likewise, have been based on matching varieties to locations, soil and climatic conditions or known pests.

In recent years, site-specific farm management has been given new life through the use of yield monitors for corn and soybean on combines in the

1. This document is SS-AGR-184, one of a series of the Agronomy Department, Florida Cooperative Extension Service, Institute of Food and Agricultural Sciences, University of Florida. First published October 2002. Visit the EDIS Web Site at http://edis.ifas.ufl.edu.

2. D. L. Wright, professor, J. J. Marois, professor, and J. R. Rich, professor, North Florida Research and Education Center, Cooperative Extension Service, Institute of Food and Agricultural Sciences, University of Florida, Gainesville, Florida, 32611.

The use of trade names in this publication is solely for the purpose of providing specific information. UF/IFAS does not guarantee or warranty the products named, and references to them in this publication does not signify our approval to the exclusion of other products of suitable composition.

The Institute of Food and Agricultural Sciences is an equal opportunity/affirmative action employer authorized to provide research, educational information and other services only to individuals and institutions that function without regard to race, color, sex, age, handicap, or national origin. For information on obtaining other extension publications, contact your county Cooperative Extension Service office. Florida Cooperative Extension Service/Institute of Food and Agricultural Sciences/University of Florida/Christine Taylor Waddill, Dean. 
Midwest. About 20\% of Midwest farms use yield monitors that were purchased with new combines (Khanna, et al. 1999). Global positioning systems have allowed variable-rate application of water, nutrients, pesticides or any number of management factors to be manipulated to better manage variability. Much has to be known about fields to vary inputs economically. Use of this technology does not necessarily mean more profit, since there are variables that are not known or that are expensive to implement. Yield maps of the same fields over years can verify if yields are being increased or level out from site-specific management. Profitable site specific management is finding the area where cost of using this technology is offset by benefits. Exact site-specific management is very difficult to determine, since biological systems can be influenced by many factors. Recent advances in computer technology, communications, and engineering have provided us with a good opportunity to change our approach to farm management, especially in relation to pest, fertility, and water management. These are the most expensive areas of input that have a large impact on yield and economics of a farm.

Farmers and those who advise them are trying to figure out how to use these new tools to their advantage. Site-specific management depends on how crops respond to the environment. These responses are due in large part to the below-ground environment (tillage, fertility, drainage, soil properties, nematodes, etc) while the above-ground environment (weather, pests, etc.) completes the response of the crop, and may be more variable, but predictions are getting better. Until crop responses can be predicted for specific management applied to management zones, and profit maps show that management is profitable, widespread adoption of site-specific management will be slow. Farmers in the southeast U.S. have been slow to adopt this technology because yield monitors are still being perfected for cotton and peanut and few are in use for these crops. This makes the outcome of site-specific management questionable and it is hard to make profit maps of fields without yields. Variable rate application of fertilizer has been the predominate use of precision technology with information gained from GPS soil sampling. Use of this technology is increasing slowly because the farm economy is suffering through low prices and farmers are not sure whether it will help the bottom line.

\section{Key to Good Decisions is Good Sampling}

Obtaining good samples or information about an area of management is the key to making good decisions. When sampling is done by zone samples (areas that yield the same or respond similarly), more is known about the field and the grower knows where responses begin and end. He may have run a harvester or grain combine over the field for many years and would know what areas or zones have similar yields or soil types and can sample accordingly. Grid soil sampling is more intensive than zone sampling and is usually done when nothing is known about the sites. Sampling field soils for nutrients has been studied intensively and at present zone sampling as appropriate for field crops has come to the forefront in the southeast U.S. Zone sampling requires knowledge of where crop yields differ in areas of the field and what "zones" respond similarly. Rapid development of sampling procedures that allow for continuous sampling of soil moisture, cation exchange capacity, and $\mathrm{pH}$, will lead to more extensive data to make better management decisions. There is a vast amount of information on crop water use and a lot is known about the water-holding capacities of most soils. However, there has been a general lack of incentives for growers to conserve water, which has slowed the commercial application of site-specific water management through irrigation systems. Use of site-specific pest management is being researched in the cotton belt, where many pesticide applications are made under conventional cotton production methods. Disease and insect pressure are good examples of sporadic pest problems that are unpredictable as to where they will occur: treatment will not affect where they occur in another season, while soil amelioration (drainage, liming, etc.) may correct the problem for years to come. Traditional integrated pest management (IPM) is based on quantification and qualification of pest populations to determine if control measures are economically viable. There has always been a tremendous challenge to quantify pest populations - and their potential economic damage — in a reasonable and reliable way. The many 
appropriate field level sampling procedures in practice today reflect the diversity of pests, their potential for rapid population growth and dispersal, their potential for economic damage, and the types of control measures available for implementation.

\section{Use of Precision Agriculture in Pest Management}

At the forefront of site-specific IPM research and application is the ability to spot-treat only those areas of the field needing pest control and to manage a healthier crop by adjusting needed inputs within the field rather than at the field level. This has a tremendous potential to reduce costs and environmental degradation. Disease, weed and nematode site-specific management is a very new area, where there is little research and almost no practical experience. Site-specific farming provides a more precise way to sample and manage fields. By linking soil, crop, pest, and environmental features into one program, crops can be managed better, with fewer trips across the field, resulting in more economic returns and reducing potential negative impacts of agricultural activities on the environment.

There has been rapid development in methods and equipment for site-specific soil sampling to sample yield on a near-continuous basis. This has been available for grain crops for some time, and is being developed for cotton, peanut, and orchard crop yields. Sampling strategies for providing appropriate pest data are also under development, especially with insects and weeds. Site-specific management for weeds is probably the newest and least advanced of the pest disciplines. However, it could one day offer the most economical and environmental benefits of any of the site-specific management areas. Soil fertility remains fairly constant over a period of years, making site-specific management decisions easier than it is for weeds, which may change within one growing season dependent on the crops and herbicides used in the rotation. Options for site-specific weed control include variable rate soil applications that depend mainly on soil type, and site-specific post-emergence applications. The goal of site-specific post-emergence application is to treat only those areas with weeds present and to treat them with the appropriate material at the right rate. Weeds tend to spread through seed or vegetatively and are likely to infest the same areas the next year. Identifying weed type and density "on-the-go" is critical to successful site-specific post-emergence weed control - it is also difficult to do with current equipment. The more information known about each field, the better the site-specific management decisions can be, offering more potential for increased profit. The remaining challenge will be to develop methods to quantify the field environmental conditions so that models can be developed to link all aspects of agriculture production within a system of precision or site-specific farming (Marois, 2000).

When developing sampling strategy for site-specific application, it is important to know the goal. For example, yield data, while useful for planning next year's activities, may not be beneficial in determining what to do in the present season. These data are not as time-sensitive as sampling for pests, especially insects and disease, which may require a nearly immediate response if a predetermined threshold is exceeded. If data are to be used in a production model, it is critical that they include adequate precision to assure that the proper management decision is made. Therefore, sampling for the purpose of developing a soil fertility map, as required in many precision agricultural activities, may be different than sampling to aid a pest management decision.

Fleischer, et al. (1999) discussed how sampling for precision IPM can be done for the development of maps to better manage the pests that vary within a field. Developed from the perspective of insect control, many of the concepts and principles developed apply to the sampling of any precision IPM activity. In traditional sampling, the goal is to get the best estimate of numbers and area of the field where the population is found. In general, a population becomes more difficult to quantify as its density decreases and areas of high population are further apart. Thus, it is often best to stratify samples to increase the probability of encountering the population. Many of the sampling plans result in a sampling procedure that is too intensive and therefore expensive. Nyrop, et al. (1999) noted that precise procedures are often unnecessary, and that more general descriptions may be appropriate when 
sampling is to provide information for decision making. It is more important to concentrate on the level of pests that trigger a management practice than to fine-tune sampling designs. Sampling data for pest management should identify where the pests are in the field and at what level. Then, rather than sampling throughout the field, it may be more efficient to concentrate on those areas where the population is expected to change, providing boundaries from which maps can be constructed. Thus the size and location of the pest clusters becomes more important than the overall mean, and it is now possible to apply spot applications of pesticides by linking the pest maps with onboard tractor or airplane GPS and automated spray application linked directly to the GPS. Fleisher, et al. (1999) and Delp, et al. (1985) concluded that placement of samples is more important in precision IPM mapping because of the need to identify the boundaries of a population. Stratified samples, distributed in a pattern throughout the field, would be used to sample plant disease.

The ability to efficiently map the distribution of pest populations will impact the future of pest management. At present, maps are being used to determine where pesticides should be applied. By integrating the pest population distribution with economic models, incorporating yield and crop value, it will be possible to determine where pest control measures should be applied, or if the potential economic return justifies application at all. By integrating potential pest population growth with density maps, it is possible to determine if and when a control action would be warranted.

The identification and quantification of the dynamics of disease spread or foci have been developed extensively (Gregory, 1968) and are assumed to be the result of spore dispersal, production, and the removal of infection sites due to previously infected plant tissue. The point of origin of the disease could be determined and would eventually become nearly devoid of spores because all of the susceptible tissue would be dead and no longer able to support sporulation. The disease foci would continue to expand, eventually forming a ring. The potential to predict where the foci are likely to occur could be an important tool in the precision application of fungicides, especially protectant fungicides that cannot stop the infection once it has begun (Zadoks, 1999).

By predicting the advancing wave of infection, it would be possible to design precision farming fungicide application that would enhance disease control and reduce the potential of resistance development. For example, the areas with visible and latent infections could be treated with a systemic fungicide, while a different spray could be applied to the invisible latent infections, as well as to adjacent infection sites in front of the infection wave that may have been contaminated with spores but not yet infected. This differential fungicide application would not only reduce the chance of resistance-development by the pathogen, but would also reduce application costs, as many of protectant fungicides are cheaper than the systemics.

Recent advances in GPS and application equipment have set the stage for rapid advancement of the application of GPS technology to disease control. New management tools have the potential to provide novel and more efficient methods of pest control, while reducing input costs and possible resistance of the pest to pesticides.

\section{Conclusion}

Precision agriculture is not a fully developed science and has not had the adoption rate of the biotech revolution, where in a period of 5-7 years, 70 million acres of cotton, corn, and soybean have been planted to transgenic varieties from conventional varieties. Growers had to make few changes to adopt this technology; they still had to plant seed and spray herbicides, but they did not have to purchase additional inputs or modify equipment. Biotech has allowed growers to do things as they had been doing them, but has made it easier, less expensive, and using less labor. In precision agriculture or site-specific management, the equipment and techniques are still being developed. It is more akin to movement from horses and mules to the tractor, which required money and development of equipment and much learning. It may take a period of 20-30 years for growers to see the advantages of using precision agriculture technology. In the 
meantime, there is enough industry support and research being conducted for new advances to be made. A survey by Khanna, et al. (1999) indicated that the Midwest would have $45 \%$ of the farms using variable rate technology in application of fertilizer by 2001. This has required fertilizer dealers to purchase equipment instead of individual growers, making the adoption of this technology fairly rapid. Doerge (1999) and others have listed several reasons growers are making the decision to invest in precision agriculture technology: 1) better information for diagnosing crop problems; 2) on-farm experimentation, especially variety trials; 3 ) improved identification of management zones, 4) quantitative evaluation of whole-field improvements, such as drainage, etc.; 5) benefits at harvest through improved truck scheduling and drying logistics, and better marketing with greater confidence of meeting contract obligations; and 6) off-farm uses such as knowing crop yield potential for insurance purposes or determining what rental prices should be paid for land dependant on yield history. Precision agriculture technology will continue to improve, offering more benefits to producers and making it common technology on farms in the $21^{\text {st }}$ century.

\section{Literature Cited}

Delp, B. R., Stowell, L. J., and Marois, J. J. 1985. Evaluation of field sampling techniques for estimation of disease incidence. Phytopathology 76:1299-1305.

Doerge, T. 1999. Yield monitors create on and off farm profit opportunities. Crop Insights, Pioneer Hybrid International. 9:14, pp. 1-4.

Fleischer, S. J., Blom. P. E., and Weisz, R. 1999. Sampling in precision IPM: When the objective is a map. Phytopathology 89:1112-1118.

Gregory, P. H. 1968. Interpreting plant disease dispersal gradients. Annu. Rev. Phytopathology 6:189-212.

Khanna, M., O.F. Epouhe, and R. Hornbaker. 1999. Site-specific crop management. Review of Agricultural Economics. 21:455-472.
Marois, J. J. 2000. Modeling in precision agriculture in Agricultura de Precisão. Pages 285-298. Borém, Giúdice, Marçal, Mantovani, Ferreira, Vale e Gomide (Eds). Universidade Federal de Viçosa, MG Brazil.

Nyrop, J. P., Binns, M. R., and van der Werf, W. 1999. Sampling for IPM decision making: Where should we invest time and resources? Phytopathology 89:1104-1111.

Zadoks, J. C. 1999. Reflections on space, time, and diversity. Annu. Rev. Phytopathology 37:1-17. 